\title{
PUBLIC PERFORMANCE OF PRIVATE INTERVIEWS: REINSERTING THE SELF INTO THE FAMILY NARRATIVE
}

\begin{abstract}
Serban Oliver Tataru and Alfred Guzzetti are filmmakers that investigate on camera the role of memory in the construction of family history. They interview family members, gather old home movies and family photographs, and dig for public archival footage, in an effort to assume their position within a personal historical continuum, and to affirm their agency within their familial community. In their creative affirmation of generational subjectivity, they push against accepted familial narratives, and use the camera as a surgical tool that troubles lingering wounds beyond the surface of old images. In Anatomy of a Departure (2012), Romanian-German filmmaker Serban Oliver Tataru interviews his parents about their decision to emigrate from Ceausescu's Romania while he was a teenager, scrutinizing on camera the conditions and consequence of a life-changing decision. While the dynamic of filming one's own family is reminiscent of home movie tropes, and the tension built around sharing delicate memories reveals an intimacy usually intended to remain private, the film proposes a multilayered performance of the authorial self. As the film reveals a self-portrait set against the familial portrait (Marianne Hirsch), an inherent performative element acts as the necessary mediator between private and public, between ethic, aesthetic and politic. Negotiating between a restorative and a reflective nostalgia (Svetlana Boym), Tataru proposes a live performance of homecoming.
\end{abstract}

Keywords: interview; performance; nostalgia; memory; family narrative; remembering; emigration.

There are filmmakers that decide to use the camera for an investigation of the relationship between memory and the construction of their own family history. In their films Anatomy of a Departure (2012), and Family Portrait Sittings (1975), the directors Serban Oliver Tataru, and Alfred Guzzetti mobilize family

\footnotetext{
* University of California, Berkeley; USA.
} 
members available to give interviews, gather old home movies and family photograph albums, and dig for public archival footage of a relevant past. The expression of their work process as visible in their (nonfictional) films attests to the authors' desire to assume their position within an historical continuum, and affirm their agency within, and belonging to, their familial community.

This creative affirmation of generational subjectivity stands as a questioning of the historically established familial narrative, where the camera becomes a surgical tool able to reach painful spots and lingering wounds beyond the surface of old photographs. The inquisitive attitude can remain implicit, the mere presence of the camera - aided be the editing - leading organically to subtle revelations of tensions between family members interviewed, or it may be openly enacted through questions addressed by the filmmakers that allow themselves a certain position of power. Such a film usually presents itself as the result of an author's going through a lengthy process of self-inquiry centered on some form of identity crisis, and is often based on questions and frustrations stemming from particular memories, and on catalytic images collected over time.

These films suggest the filmmakers' preoccupation to provoke a moment of communication with their parents, a process that for these authors seems to work as necessarily mediated through performance. The filmmakers develop the representation of a dramatic and seemingly private instance of familial connection within the means and scope of a performative frame. This seems to suggest the authors' assumption of a direct relation between the quality of the specific intergenerational exchange, and the publicizing of its filmic representation. One can ask, then: to what extent do the authors see filmmaking as a means for - and guarantee of - reaching out to their elders? To what extent are these films enacting the artists' repressed desire to be listened to, to be recognized as subjects within their families, and not of their families? In an attempt to provoke a moment of communication with their parents, these filmmakers mobilize specific stylistic modes of expression into a performative work whose intended public finality comes as the sacrifice that validates their agency as members within their familial communities. While my analysis will focus on Serban Oliver Tataru's Anatomy of a Departure, I will refer to Alfred Guzzetti's Family Portrait Sittings as a similar approach of cinematic representation of strained family dynamics, placed in a different socio-cultural and historical context. 
Re-writing, Re-imagining the Past (III)

\section{Family as Belonging}

In his 1975 film Family Portrait Sittings, Alfred Guzzetti looks back at the history of his family from its origins in Italy to present day Philadelphia. He films interviews with his maternal grandmother, maternal grandfather's brother, and parents at home, and records his paternal grandfather's cousins form Italy. He lets their words linger and resound over black and white footage of streets in Abruzzo or Philadelphia, over pans of different rooms inside houses throughout these places, and over old home movies revealing different moments from the narrative of a family that had the privilege of owning a film camera since the early $20^{\text {th }}$ Century.

Guzzetti appropriates the home movies shot by him and his father within a chronological narrative shaped by the relatives' testimonies. He inserts his authorial presence within the conversational flow by formulating questions that bring the interlocutors - especially his parents - on a mined territory: the tension is palpable within the tone of the parents' addressing each other. The parents reconsider their memories as they respond to Alfred who voices his questions from behind the camera. While his audible presence affirms his active participation in shaping the direction of the discussion, the filmmaker remains absent from the frame: the wall behind the sofa on which the parents are seated facing the camera is completely covered by a mirror, but Guzzetti places himself such that he is conspicuously absent from the mirror reflection. This audio-visual play around presence and absence echoes the substance of his questions towards his parents. He asks them why they decided to move from South Philadelphia. William Rothman comments interestingly on this: "This question has an edge to it. We sense a long-standing conviction that this move was a mistake - a mistake that caused the filmmaker untold grief." (Rothman 202) Later, Guzzetti asks them why they decided to send him to parochial school. Through his questioning, the filmmaker brings his parents to retroactively acknowledge his individuality as a child - to accept and address his perception of them as not having considered the child he was as a partner in the decision making process. William Rothman analyzes the dynamic of these scenes: "The shots that expose the parents' competition for narrative authority expose as well the theatricality of their routines, reveal them to be performances directed to a present audience. Their attempts to set the record straight are also performances of old routines directed, now as always, to their son." (Rothman 201) The camera, I would argue, is the one to actually direct and guarantee the parents' attention to their son, or to 
locate him as the focal point of their attention. The presence of the camera modifies their behavior in two directions - on the one hand, they make efforts to restrain their reciprocal agressivity. On the other, while addressing Alfred's questions, they go through pains in trying to keep a balance between their own memories of the facts, and the reproaching suggestions implied in his words.

The whole setting speaks for the performers' understanding of, and agreement to, the rules of the game. The parents are not at ease, and their son directs their performance by asking them to sit on the sofa, and speak to the camera - thus to him, and to us - about issues that usually do not go on record. The performance consists in Guzzetti's mastering of a conflictual situation in which he has the performers' agreement to expose themselves for an unknown audience. Even more, this is also the director's self-performance, as the intimacy of the relation between the three would relay any revelation back to his subjectivity. Guzzetti remains indeed in power, as Rothman argues, but this power is hardly won, and painfully sustained - the more incisive he becomes through his inquiries, the closer he gets to being perceived as betraying the participatory trust of the parents.

\section{Family as Home}

In his film Anatomy of a Departure (2012), Romanian-German filmmaker Serban Oliver Tataru interrogates his parents about their decision to emigrate from Ceausescu's Romania while he was a teenager, scrutinizing on camera the conditions and consequences of a life-changing decision. While building his film around video interviews with his parents, Tataru incorporates images from his recent journey to Bucharest, the city he left as a teenager in 1989, as well as family photographs from his childhood placed in a context suggested through archival footage from old Romanian television broadcasts. Tataru speaks from the perspective of the son that attempts to reassemble a family image that has been taken away from him. He challenges the official version of familial memory while he questions his exclusion from the decision taken by his parents twentytwo years back. Within a courageous act of performative authorship, Tataru takes on the role of his 13-year old self and asks the question he could not ask at the time: Why he was not told that his father left for Germany determined to remain there?

The filmmaker provokes and exposes the parents' discomfort when forced to acknowledge and reassess the perspective of the son, as the camera records 
every visual and aural detail of their surprised expressions. Tataru's project comes across as the conscious (and seemingly consensual) organization of the context of a private conversation into the public event constituted by a documentary film. The interviews' mise-en-scene, and the sensitive nature of the discussion shape the parents' interventions into forms of testimony. Jeffrey Skoller writes that "the testimony is often made out of a sense of duty with the implication that what will be revealed is necessary for others to know." (Skoller 133) Tataru presents the parents' delivery as a performance for a public, for a viewer outside the family, a performance that mediates the filmmaker's autobiographical reflection. At the same time, Tataru annotates the evocative images of the film in a first-person voice-over, where the pronoun ' $\mathrm{I}$ ' enacts Tataru's multifaceted identity as the filmmaker, narrator, and subject of the film by successively allowing insights virtually available to only one of these identities. The performative construction of the Anatomy of a Departure stands as the filmmaker's expression of a transformative processing of nostalgia. Throughout this process, Tataru balances visuals against sound as he constantly negotiates between representations stemming from a restorative form of nostalgia, and a critical assessment based within a reflective nostalgia.

For Svetlana Boym, "nostalgia is a longing for a home that no longer exists or has never existed"; it is also "a yearning for a different time - the time of our childhood, the slower rhythms of our dreams," and "for the unrealized dreams of the past and visions of the future that became obsolete."(Boym xiii, xv, xvi)) In Tataru's vision, the interrupted adolescence - as the time 'before' and 'after' the departure of his father - is internalized as a rupture, a painful discontinuity that marks the loss of familial safety and security, and that is inscribed in memory as a missed, virtually happy(er) alternative, thus the source of a nostalgia for a time never experienced, for a promise never actualized.

According to Boym, nostalgia is manifest within two components: restorative nostalgia, and reflective nostalgia: "Restorative nostalgia stresses nostos and attempts a transhistorical reconstruction of he lost home. It does not think of itself as nostalgia, but rather as truth and tradition. It protects the absolute truth." (Boym xviii)

Reflective nostalgia - thrives in algia, the longing itself, and delays the homecoming. It dwells on the ambivalence of human longing and belonging, it calls the truth into doubt. It does not follow a single plot but explores ways of inhabiting many places at once and imagining different time zones. At best, 
reflective nostalgia can present an ethical and creative challenge. (Boym xviii)

Anatomy of a Departure expresses the filmmaker's negotiation between a restorative need for returning to the sensorial presence of the past, and a reflective assessment of the roots of this longing. This exploration prioritizes the act of expression over its effect, the process over its finality. The questions and answers exchanged in the film are not meant to elucidate and re-order the past, but rather to open unexplored ways of reflection as the filmmaker remains aware of the illusory character of his longing.

The film reconstructs memory as the locus of multiple perceptions of a past that is contextually retrieved through preferences of remembering that differ between parents and son. From Tataru's perspective, the memories are arranged in successive layers according to his level of affective engagement with the past. As such, for the filmmaker the whole project foregrounds the reassessment of the relationships between the family members as affected by the father's unexpected leaving - for Tataru, this reassessment is a necessary endeavor, as the perceptions of these relationships are subjective, and often painfully divergent. The filmmaker places the memories of everyday life, reflected mostly in the firstperson actualization of space and place, on a secondary plane, as the frame of the familial dynamic. Lastly, the memory of the socio-political context of Romania in the 1980s, as reflected in the remediation of archival television footage, is visible in a more distanced background. This mnemonic preference, expressed within particular stylistic treatments of image and sound, serves as the structure for the film, and is enhanced by the contrast with the parents' priorities of remembering. From the parents' perspective, the memory of their perception of the social and political past overlaps with their remembering of everyday life, and the compounding of these registers of memory overdetermines their perception of the family's past. For the parents, the process of memory excavation is both unpleasant and unnecessary, and this is succinctly alluded to by a touching voice-over observation of the son-narrator: "When I showed my parents the footage from the Romanian National Archives, they looked at the clips I have chosen for the film but didn't ask to see the rest of the footage. I was disappointed - I had hoped we'd watch it together and remember."

While scouting the city space in search for the place that shelters his memories from twenty years back, Tataru climbs on the roofs of Bucharest's apartment buildings where the time stood still. His essayistic voiceover impregnates the images with a transcendent alterity that operates a temporal and 
spatial sublimation - we are transferred into the here and now of the past as we get to feel the weight of lived experience within small details of communist impersonal gray buildings. If this geographical memory accounts for a firsthand experience of the Romanian pre-1989 reality, the mediated image memory completes the construct of cultural identity. Tataru's manipulation of found footage is less about the futility and seeming ridicule of the expressions of communist ideology, as rather about the way this social and political context shaped his growing up from a distance, in a muted and ironical way. As a child, he lived through the system, and proudly became a pioneer (the young communists with red scarves), while at the same time making fun of the slogans, under the naïve immunity allowed by the young age. Counterbalanced by the commentary, the found footage images provide the context for a narrative that places the film within a continuum between micro-, macro- and global history. The migration experience of a family stands in as one of the many similar within a nation that lived through the failed promises of the construction of socialism.

The video interviews negotiate the different perceptions of the dynamic of family relations following the father's leaving for Germany. This difference is first visible at the level of the language used - while both parents are living in Germany, during the interviews, the father, Marius Tataru, speaks German, and the mother, Adriana Tataru, speaks Romanian, while the filmmaker addresses them accordingly. ${ }^{10}$ Marius Tataru has German roots through his father, a Saxon living in Transylvania, so for him speaking German comes naturally. However, beyond their choosing of the language in which they are most comfortable, we sense that this attitude reflects a certain way the parents choose to situate themselves in front of the camera, and in relation to the subject of discussion. This is almost made explicit in the words with which each of them starts. While trying to defend himself when his son claims that he doesn't want to recall the events for the film, Marius replies throughout a dialogue: "You expect me to say what a big thing this was - but I never said it was anything special. [...]But it's very hard to explain or describe. It's an intimate thing. After all, it boils down to very little. Little, but very emotional. But not a big thing." For the father, the language of speech - German, as removed from the language of his Romanian past - works as an extra mediation, a screen meant to protect the intimacy

\footnotetext{
${ }^{10}$ Tataru's voiceover commentary is in German as well - one of the considerations in this decision was the German context of the production of the film. (personal conversation)
} 
aggressed by the son's questioning on camera, the last redoubt before having to face his promise of speaking up. From the first words exchanged between son and father in German, Romanian colorful idioms slip in, spicing up their communication with the meaningful flavor of the native language.

Adriana, the mother, starts by talking about the trust between parents and child, about "the three of us always trusting each other." She remains aware of the direction of the conversation, as she pauses and amends her thought, ready to take on the implied, not yet spoken reproach of her son: "That is, until your father left. It may have looked like we didn't trust you, because we didn't tell you. But that's not true." Adriana is defensive of her own memory of the past, but she is also welcoming, smiling and willing to share, while openly giving herself to this experience. For the son, the moment of Marius's definitive leaving felt as a violent, unexpected splitting of the family. Together with his mother, Serban spent the following two years selling or giving away their belongings in a methodical, piece-by-piece dismantling of their apartment. During this time, Adriana sustained the every-day psychological battle of going through the perverse hoops of a system that, while officially abiding by the law that guarantees the emigrant's family's right at reuniting, would always invent new means of impeding on anyone's leaving the country.

As first-person narrator, Tataru sets an autobiographical tone that allows room for a discourse at once intimate and analytical, a discourse that starts from a personal, physical return home, and grows toward a collective, symbolical act of recuperation. Tataru tackles the collective dimension by reaching out to his parents. Through his interviewing, Serban directs his parents to chronologically retrace the course of the events while sharing their feelings at the time. He addresses them individually, as he tries to reconcile his own affective recollection of the past with their respective versions. Each of the parents' medium close-ups fills the frame, while they are oriented complementary as if the camera is placed in between - Adriana faces slight to the left of frame, Marius slightly right. While they speak, they look at Serban, and not into the camera. This mise-en-scene contributes to an increased sense of intimacy - is seems that everybody is in the same room while engaged in a conversation from which we only see one of two participants at a time, and only hear the third one. But the two sets of dialogues run in parallel, Serban addressing each parent alone, and as the conversations become more dramatic, the interlocutors are more expressive and engaged in their performances. Despite their willing participation in the project, the parents 
seem to affirm an initial defensive position, a preemptive resistance to a direction of discussion they see coming. At the same time though, this posture is immediately short-circuited by details of expression, by small reactions hardly distinguishable in the tone of voice or in the use of language, that communicate a productive potential behind the resisting façade. It is here, in these cracks and fissures of the parents' appearance, that Tataru identifies the signs of an affective memory that could be worked into that capacity of reflective nostalgia that, according to Boym, "awakens multiple planes of consciousness." (Boym 50)

For the first part, Marius's initial reaction to each question is of suspiciously glancing at his son, as if thinking 'What does he expect me to say now? Why this question now?' His answers are delivered in an imperative tone, slightly raised voice, through a fast paced wording further emphasized by the editing - he hardly ever pauses for a breath, like in an effort to be finished once and for all. There is though a moment when his demeanor changes, and, as he becomes more reflexive and cooperative, he seems to finally accept his role. At the 46 minute into the film, he admits the usefulness of the inquiry when he finishes a dialogue with: "Now that you're asking me, I remember because I haven't asked myself for a long time: how I coped back then." Marius gives his most touching delivery when revealing his brother's complex situation in relation to their leaving: as a University professor and officer of Securitate, the brother represents the big-brotherly-eye of the system, the one who would always be asked to give his guaranteeing consent for any trip abroad made by Marius. The latter's fleeing triggered long-lasting consequences for Bobby's career and life. After repeated failed attempts, Serban convinces Marius to talk about Bobby - the father speaks at peace to himself, in a moderate tone, carefully looking for the right words to express the complexity of his feelings. The visible shift in Marius's attitude suggests his coming to terms with certain insecurities and anxieties that, as an art critic, he may be acutely aware of, and that I would see reflected in Marianne Hirsch's writings about gazing at family photographs from outside the familial look:

As I think about these photographs, however, I realize that one of the primary elements of the familial look is that it occurs within a closed circle. What happens when that circle is enlarged to include other viewers and readers? [...] [W] hat is my readers' relationship to my family images? What kind of look mediates between the protective circle of the familial and the public scrutiny of academic writing? What are the ethics, what are the politics, of this "exposure," 
University of Bucharest Review $\propto$ Vol. XI/2021, no. 1 (new series)

Re-writing, Re-imagining the Past (III)

this public reading of images that generate their meanings in the private realm? (Hirsch, Family Frames 107)

I would argue that, in the case of the filmic familial portrait, a certain inherent perfomative element is the one to mediate between private and public, between ethic, aesthetic and politic. Throughout its layering, Anatomy of a Departure proposes a multiple performance of the authorial self. Serban Oliver Tataru performs vicariously as reflected within his parents' "acting" - their delivery functions as a mirror that both projects the son's retrospective identity search, and sends it back with no real closure. But although he would allow his own visual presence only as the child looking back to us from old family photographs, Tataru performs more directly through his reflective voiceover. While following an affective topography of remembering through a spoken description of memories of feelings and events in relations to images of places, he steps back and questions the whole construction of the edifice of his film: "Why am I dragging images of my past through the streets? And examine them like $35 \mathrm{~mm}$ slides? Why do I rejoice every time when the images match? Why am I conducting endless interviews with my parents?"

It is as if the parents' moments of self-reflexivity inspire the attitude of the son-filmmaker, and ease his way into processing different registers of nostalgia. The film's layering of expressive registers recalls Svetlana Boym's characterization of reflective nostalgia as "oriented toward an individual narrative that savors details and memorial signs, perpetually deferring homecoming itself. This one reveals that longing and critical thinking are not opposed to one another, as affective memories do not absolve one from compassion, judgment or critical reflection." (Boym 50)

As the son, the interviewer, the narrator, and the filmmaker, Serban Oliver Tataru repositions his social actors as parents, interlocutors, subjects of narration, and film characters. These performative devices allow him to navigate between essayistic, evocative, inquisitive, and self-reflexive voices, in an attempt at reassessing the arrangement of the participants within a family portrait shaped at the intersection between memory and history. For Tataru, this gesture stands as a reflective working of nostalgia through an analytical dissection of a homecoming that, while symbolical, remains both desired and loathed, always longed for and perpetually deferred. 


\section{Conclusion}

Within their sensible and fine-tuned construction, these autobiographical works interrogate inside perceptions and practices of the family institution, while reaffirming the importance of familial structure. As such, the films speak from an insider perspective, and expose conflicts located in the familial past that, although buried and never brought up, seem to reverberate in the affective psyche of the filmmaker. These conflicts bring to the fore the filmmakers' perceptions of their exclusion from important family decisions that would further affect their lives. The films give expression to feelings of identity anxiety developed from tensions related to a process of moving and displacement the directors have been subjected to as children or young adolescents.

Most significantly, these works employ performative modes of filmic construction in order to enable the translation of the personal and private into the public. One mode of performance refers here to the filmmakers' constructions of self through their projections on, and reflections of their families. For each author, this attempt seems to constitute a creative process of healing, allowing an introspective analysis of the role of memories in the construction of family history. The other mode of performance refers to the public exhibition these authors intend for their works. The familial collaborations that these films necessitate culminate with the gift of the family to the filmmaker - by agreeing to be recorded and publicly displayed, the family embraces its son in a gesture that stands as acknowledgment of his belonging to, and agency within the familial community. For us, the audience, this performance mediates the partaking in other people's intimacy. At the same time, our witnessing of alternative personal experiences leads to a reconsideration of the meanings of family belonging and participation, and to understanding family as a community both determined and marked by its past, while shaped by its multiple histories allowed by as many individual memories.

\section{Works Cited}

Boym, Svetlana. The Future oof Nostalgia. New York: Basic Books, 2001.

Bummer, Angelika, ed. Displacements. Bloomington: Indiana University Press, 1994. Print.

Hirsch, Marianne. Family Frames: Photography, Narrative and Postmemory. Cambridge: Harvard Univesrity Press, 1997. Print. 
Hirsch, Marianne, ed. The Familial Gaze. Hanover: University Press of New England, 1999. Print.

Ishikuza, Karen, and Patricia Zimmermann, ed. Mining the Home Movie. Excavations in Histories and Memories. Berkeley: UC Press, 2008. Print.

Lebow, Alisa, ed. The Cinema of Me. The Self and Subjectivity in First Person Documentary. London: Wallflower Press, 2012. Print.

Macdonald, Scott. American Ethnographic Film and Personal Documentary. Berkeley: UC Press, 2013. Print.

----."The Home Movie and Space of Communication" in Rascaroli, Laura, and Gwenda Young, ed. Amateur Filmmaking. The Home Movie, the Archive, the Web. New York: Bloomsbury, 2014. Print.

Rascaroli, Laura, and Gwenda Young, ed. Amateur Filmmaking. The Home Movie, the Archive, the Web. New York: Bloomsbury, 2014. Print.

Rothman, William. The "I" of the Camera. Essays in Film Criticism, History and

Aesthetics. Cambridge: Cambridge University Press, 1988. Print.

Skoller, Jeffrey. Shadows, Specters, Shards. Minneapolis: University of Minnesota Press, 2005. Print.

Tataru, Serban Oliver. Filmmaker's interview

http://oneworld.ro/2013/1/ro/stiri/130/interviu-serban-oliver-tataru-regizoranatomia-unei-plecari/ Accessed on 05/04/2014.

Anatomy of a Departure. Directed by Serban Oliver Tataru. 2012.

Family Portrait Sittings. Directed by Alfred Guzzetti. 1975. 